\title{
Students' Perceptions on Teaching Styles within Public International Law Curriculum: a Case of Russia
}

\author{
Anastasia Belousova \\ Peoples' Friendship University of Russia (RUDN University), Moscow, RUSSIA \\ Marianna Ilyashevich \\ Peoples' Friendship University of Russia (RUDN University), Moscow, RUSSIA \\ Yekaterina Kupchina \\ Peoples' Friendship University of Russia (RUDN University), Moscow, RUSSIA \\ Alexander Belousov \\ Peoples' Friendship University of Russia (RUDN University), Moscow, RUSSIA
}

Received 16 April 2017 • Revised 28 March 2017 • Accepted 26 July 2017

\begin{abstract}
The topicality of the research is stipulated by the challenges the legal education faces due to the controversial trends toward globalization and national legal system preservation, toward comprehensive legal training on the one hand, and the market increasing demand for narrow-field practitioners. The aims of the research are to study law students' perceptions regarding teaching/learning formats of studies in progress, to follow the development of students' perceptions regarding their legal studies at different levels of higher education. The research methods included theoretical analysis, law students' survey, statistics data processing. The empirical studies included two surveys: the entry survey of second year students of LLB and the same students' survey when they have moved to the second year of their master studies. The research enhances the awareness of the specific characteristics of public international law teaching within national system of legal culture and its values. The empirical data contributes to teachers' understanding of students' needs and raises awareness of learner-centered education within legal domain. The article had both theoretical and practical value as the theoretical background and the proposed methodology can be applied to developing training courses for legal faculty.
\end{abstract}

Keywords: legal education, public international law, learner-centered education, interactive training

\section{INTRODUCTION}

The modern legal education is traditionally considered as an important factor of the nation development within both national and international contexts. Currently this domain of higher education faces debates and disputes regarding the scope and contents, the recommended formats of training, applied of theoretical focus in training, skill-based versus fundamental knowledge-based training, pragmatic or humanistic approach to professional values of lawyer-to-be.

(C) Authors. Terms and conditions of Creative Commons Attribution 4.0 International (CC BY 4.0) apply. Correspondence: Anastasia Belousova, Department of International Law, Law Institute, Peoples' Friendship University of Russia (RUDN University), Moscow, Russia. 


\section{Contribution of this paper to the literature}

- $\quad$ The research provides fresh empirical data on law students perceptions regarding their preferred styles of learning at different stages of their education. New educational field is in the focus, covering the issues of legal education.

- The research allowed for distinguishing the students' attitudes to learning formats with regard to the students' learning experience and type of their academic program. The experiment confirmed that the more experience students get in their field of studies the more demanding they become regarding interactive learning formats related to the profession real settings.

- The study made it possible to specify students' perceptions regarding concrete forms of training, including lectures, colloquia, Socratic dialogues, problem solving, simulations, creative tasks, mooting. The empirical analysis also allowed for identifying benefits that the above forms bring to different stages of universitybased legal education. The research results reveal the ways to balance various learning formats and tailor the legal studies curriculum to BA or MA students' needs.

Meanwhile, the shifts and moves within the above multidimensional environment can lead to rather different outcomes in legal training regarding the level of professional expertise, its self- perception by the law school graduate, and his or her future activities.

Further, it is really important to develop students' reflection skills on their studies in general, and law students' reflection skills, taking into account the role of reflection in legal profession (Leering, 2014).

Moreover, the above issues come across confronting voices over globalization of law and national legal systems specifics rooted in the long standing historical traditions of nations.

Against the mentioned background there are statements that international law training formats are globally spread and the same across countries, universities, levels of higher legal education (Nowrot, 2004).

The main goal of this paper is to explore law students' perceptions regarding teaching/learning formats of studies in dynamics, i.e. to trace the development of students' perceptions regarding their legal studies at different levels of higher education, namely LLB and LLM programs.

The goal is expected to be reached through the following tasks: literature analysis on legal training practices and prospects, law students' surveys on their preferred formats of studies with additional explanations on the reasons for expressed preference, analysis of variables significance regarding students' opinions.

\section{LITERATURE REVIEW}

The modern higher education strives to develop the personality of a student, his/her individual abilities; to assist the learners to get diverse knowledge, skills and know-how necessary for their prospective realization in the future professional (Hüfner et al., 1997).

Legal education has become one of specific issues within the Higher education studies due to it high profile impact on modern society development and future generations life (Reed, 1999, Webb, 1998). The above has led to specific legal documents regarding legal education (RF President Decree, 2014).

Scholars underline the importance for legal education to contribute to promoting intellectual development, spiritual growth or the broadening of one's horizon in general and argue for a combination of various approaches and forms of delivering and shaping students' legal knowledge (Van Klink \& de Vries 2013; Sommerlad et al., 2015).

Stakeholder underline that special attention should be paid to development and use of such methods and tools that could motivate students, enhance their self-reliance, promote creative approach to learning, develop practical skills, as well as in the ability to anticipate a real situation of professional activity. 
Current research on legal education specifies the importance of the constructivism philosophy (Vanderstraeten, 2002) and humanism principles application, competence-based approach (Sturm \& Guinier, 2007), learner-centered interactive training (Barton \& Westwood, 2011).

Scholars underline the importance of search for integrated techniques to teach law, appreciate experimental teaching to weight and compare divers teaching/learning practices (Qafisheh, 2016).

Legal educators insist on the importance of Legal Theory and Methodology issues in the legal education contents (Sokhi-Bulley, 2016), agree on the importance of the students' engagement in empirical research (Hutchinson, 2016), underline the need for comparative approach to studies (Germain, 2016), argue for visualization and performance through case studies (Del Mar, 2016).

Researchers on legal education agree on the importance to combine various formats of studies. Educators outline the following widely accepted teaching/learning forms within the curriculum:

1) lecture; and it seems importance to mention the difference between traditional versus engaging lectures, that are also called broken or interactive lectures, in the course of which students are given short periods of "breaks that can consist of short papers, problem sets, brainstorming sessions, or open discussion (Miller et al., 2013, p. 347-348); moreover, it seems reasonable to distinguish also quest lectures by internationally recognized visiting professors and practitioners from international intergovernmental organizations;

2) various types of seminars, including

- colloquia seminars with the view to estimating the level of theoretical knowledge in addressing specific problems and tasks (Sokhi-Bulley, 2016); this kind of seminar offers students a wide range of sources is offered for seminar preparation;

- seminars using Socratic dialogue format that in the form of questions, answers and debates provides the opportunity for sharing theoretical knowledge requires a deep immersion in the problematic aspects of a particular problem with the mastery of a vast theoretical material, primarily of a doctrinal nature. This allows comparing the doctrinal positions of various schools of international law on the most controversial issues and, if possible, developing individual point of view based on the appropriate legal argumentation (Areeda, 1996);

- problem-solving seminars in an interactive form when subgroups of students are offered only one specific international legal problem for consideration in an interactive form as the above problem solution can be reached by using different approaches (Menkel-Meadow, 2001);

- professional simulations, i.e. simulation of meetings or negotiations within various international judicial bodies when students are assigned various roles, which implies the most accurate performance of the functions of a particular specialist (Barton et al., 2007);

- creative tasks with critical thinking focus within the seminar; for instance, such tasks can include an analysis of the provisions of a specific treaty, systematic assessment of the arguments of the parties to the dispute from the position of the judge with the use of various methods of interpreting the provisions of law (Menkel-Meadow, 2001, Montgomery, 2007).

3) mooting (as part of extracurricular activities) include organization and preparation of the university team to participate in the international legal competitions; the above activities imply that a student team is set up to elaborate legal positions and their further presentation in the international court; legal educators underline that is a really specific form of assessment in legal education (Lynch, 1996).

The literature review paved the way to students' surveys design and implementation. 


\section{MATERIALS AND METHODS}

The research followed qualitative approach to analysis and incorporated theoretical and empirical activities. Materials for theoretical analysis involved research papers on the issues under study. Their critical investigation paved the way to identify the research problem and elaborate on the methodology for empirical activities that included several stages, including the empirical research overall scheme development, target audiences' identification and preliminary explanations to enhance students' understanding purposeful engagement in the experiment, the open-ended questionnaire drafting, students' survey, and the results thereof processing, as well.

The empirical analysis was a kind of longitudinal study as it encompassed law student cohort opinions during the learners' studies on their second-year studies on BA program on International Law, and then, during their second-year studies on the MA program on the International Law.

Thus, empirical analysis aimed to evaluate the target audience' perceptions at two different time periods, with two-year long gap.

The empirical analysis took place at the Law Institute of Peoples' Friendship University of Russia (Moscow) that is really international university and enrolls annually students from over 150 countries.

The survey engaged three flows of students that totally amounted to 103 participants, first during their being second year BA students, and then, second year MA students.

The open-ended questionnaire was practically the same for both surveys. It listed the formats of studies mentioned in the section of Literature review. Students were asked to answer the following questions:

- Do you consider this format of study useful? (yes/no) Why? (Answer in free style)

- Think of the percentage distribution of training time among these formats (if possible give reasons for your choice).

The factor analysis was used to specify students' perceptions on the teaching/learning process at different periods of their studies at different stages of higher education (bachelor and master levels). The t-test was applied to explore the importance of different variables.

The survey took into account the gender, age, year of studies, cultural background (respondent's affiliation to eastern/western culture), geographical origin (small towns/industrial cities). The variables have been identified with reference to existing data on the grounds for student perceptions' diversity (Astin, 1993; Li, 2012). SPSS was used for data procession.

\section{RESULTS AND DISCUSSION}

The research revealed that university students prefer to integrate theoretical and applied training and value interactive formats though at different stages of their education students view the relevance of a concrete format differently.

Figure 1 shows BA students' opinions and Figure 2 reveals MA students' attitudes. The diagrams provide average percentage that students related to the share of each training form within the overall course of international law subjects.

The comparative analysis of data proved that students' learning and overall social maturity lead to the significant changes in their perceptions of the learning formats students need for further professional activities. Along the move from BA to MA level students consider lectures, colloquia seminars, and isolated problem solving as less suitable. The statistics confirms over three-fold decrease from $30 \%$ to $8 \%$, nearly two-fold decrease from $15 \%$ to $9 \%$, and one third decrease from $15 \%$ to $10 \%$ indicating the relevance of the training formats, respectively. The figures prove that students when growing require more interactive formats related to the profession real settings.

The factor analysis helped to understand reasons for the above changes. 


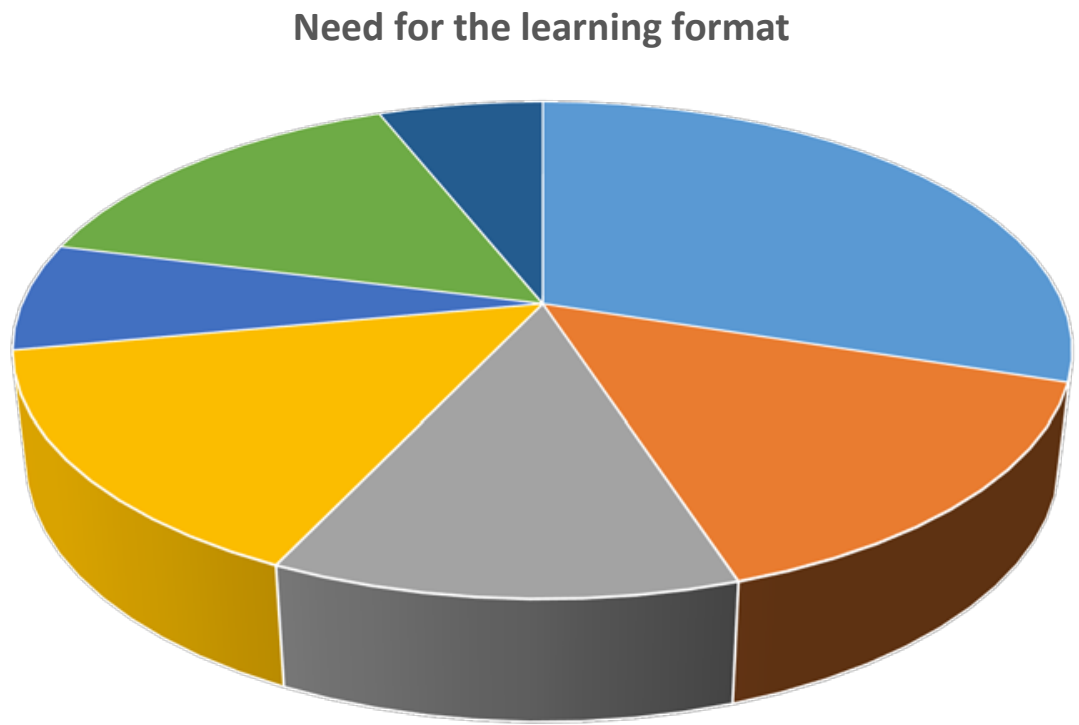

- lectures - colloquia $\mid$ socratic dialogues $\mid$ problem-solving " simulations " creative tasks - mooting

Figure 1. BA students' opinions

\section{Need for the learning format}

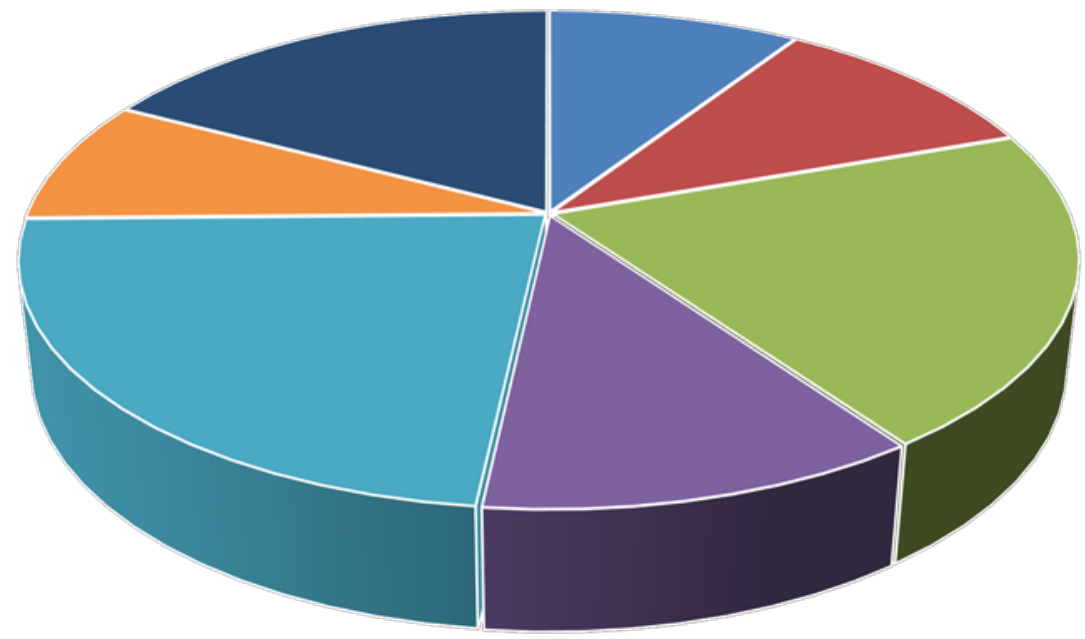

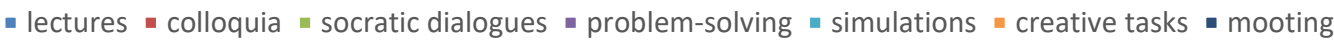

Figure 2. MA students' attitudes

Integrated analysis of students' responses during their studies at BA and MA levels confirms that agreed that the lecture and colloquia help to detailed, deep and systemic understanding of normative sources (international treaties and other international legal acts), and doctrinal sources, the preference is given to textbooks and monographs in various foreign languages. Moreover, the respondents underlined that the above formats of 
learning highlight the most important aspects of the problems, and put complex and controversial questions requiring a certain level of independent analysis based on systematic nature of the already acquired knowledge. Meanwhile, respondents have stressed that such kind of knowledge is not the top goal of MA students who strive to engage in real professional settings; the item was mentioned by $87 \%$ of the respondents. Moreover, the above percentage of students specified the importance of interactive lectures conducted by guest professors and officers from international institutions. This can be explained by the assumption that such activities enhance students' awareness of the legal profession international environment.

Nonetheless, the discriminant analysis identified as statistically significant $\left(\lambda=0,243, \chi^{2}=4,65, p<0,01\right)$ respondent cultural affiliation to the eastern/ western culture. Fewer students who affiliated themselves with the western culture mentioned the need for lectures and colloquia in the curriculum.

On the other hand, the data confirmed students get even more interested in learning in the settings that mirror real world of legal profession in diverse contexts.

When going up from BA to MA programs students start strongly appreciating and vote for simulations, mooting, Socratic dialogues, and retain their interest towards creating tasks, as well. The comparative analysis of the first and second diagrams figures reveal nearly three-fold increase from $7 \%$ to $20 \%$, over two-fold increase from $6 \%$ to $15 \%$, and $30 \%$ increase from 12 to 18 meaning, regarding the mentioned formats of training, relevance, respectively.

The factor analysis explained the grounds for the above state of affairs.

This form of training allows students to master the skills of working with sources, time management for elaborating the position and highlighting the key and most significant arguments. The factor was mentioned by $83 \%$ of the respondents.

While preparing the task, students are advised to use materials in the original languages: Acts of international and regional intergovernmental organizations, the practice of different states, international judicial bodies and others. This also enhances students' practical experience; the item was mentioned by $81 \%$ of the respondents.

As for simulations, they assume a comprehensive analysis of normative and other materials, as well as viewing the video and audio materials of various hearings of a particular organization. This work allows students to master the skills of working in the courtroom, being immersed in the real practical settings. This item was mentioned by $78 \%$ of the respondents. As an example, students mentioned their participation in simulation of the Dispute Settlement Body within the World Trade Organization.

Another example mentioned by the students concerned the simulation of international negotiations with a view to drawing up and concluding an international agreement. The experimental data confirms the research team preliminary assumption that simulations allow for developing the creative potential of students, their ability to activate their skills of team work for negotiating and balancing diverse positions.

Nonetheless, again the discriminant analysis identified as statistically significant $\left(\lambda=0,221, \chi^{2}=4,07, p\right.$ $<0,001)$ respondents' cultural affiliation to the eastern/ western culture.

Less percentage of the students who affiliated themselves with the eastern culture mentioned the need for interactive formats, including simulations, mooting, Socratic in the curriculum.

The discriminant analysis data goes in line with theoretical assumptions that have been outlined in previous research (Dent, 2005). The data requires further research and draws law teachers' attention to the culturally sensitive formats of legal training. 


\section{CONCLUSION}

The research data elaborated one law students' perceptions regarding teaching/learning formats of studies in dynamic paradigm, allowed for associating the change in the mentioned perceptions with students' studies at different levels of higher education, students' educational values from a cultural perspective. The findings helped to understand students' priorities with the view to learning formats and styles.

The research findings contribute to enhancing the concept of interactive teaching of international law. The domain of training will gain if various methods of educational and cognitive activities are combined through integrating verbal and performance methods (narrative story, dispute, explanation, etc.), theoretical and applied training (lecture and practical tasks), deductive and inductive methods, research-led training with various level of investigation (from concrete search towards full-scale research), etc.

The university-based teaching on Public International Law takes into account internationally recognized standard forms of training and assumes that a qualified lawyer should reach civil maturity and follow national specifics of professional legal ethics, of legal and psychological culture. Curriculum design of academic programs on Public International Law requires careful understanding of peculiarities related to the teaching subject, target audiences, educational and professional contexts.

\section{REFERENCES}

Areeda, P. E. (1996). The Socratic Method, Harvard Law Review, 109(5), 911-922.

Astin, A. W. (1993). Diversity and multiculturalism on campus: How are students affected? Change, 25(2), 44-49.

Barton, K., McKellar, P., \& Maharg, P. (2007). Authentic fictions: simulation, professionalism and legal learning, Clinical Law Review, 14(1), 143-93.

Barton, K. \& Westwood, F. (2011). Developing professional character - trust, values and learning. In: P. Maharg, \& C. Maughan (Eds.), Affect and Legal Education. Emotion in Learning and Teaching the Law. Aldershot, Ashgate Publishing, 235-257.

Del Mar, M. (2016). Learning How to Read a Case: Resources from the Visual and Dramatic Art. In: Bart van Klink, Ubaldus de Vries (Eds.), Academic Learning in Law, Edward Elgar Publishing, 244-266.

Dent, M. (2005). Designing an LL.M. Curriculum for non-Western-Trained Lawyers, Perspectives: Teaching Legal Research Writing, 87, $13 . \quad$ Retrieved from https://info.legalsolutions.thomsonreuters.com/pdf/perspec/2005

Germain, S. (2016). For a New and More Diverse Comparative Legal Education. In: Bart van Klink, Ubaldus de Vries (Eds.), Academic Learning in Law, Edward Elgar Publishing, 180-200.

Hüfner, K., Sadlak, J. \& Chitoran, D. (1997). Research on Higher Education and the Activities of International Organisations: Multiplicity of Interests, Needs and Forms. In: J. Sadlak, \& P. Altbach (Eds), Higher Education Research at the Turn of the New Century. Paris, New York and London: UNESCO and Garland, 321-347.

Hutchinson, T. (2016). Empirical Methodologies Knowledge and Expertise: A 'Necessary' Skill for Lawyers? In: Bart van Klink, \& Ubaldus de Vries (Eds.), Academic Learning in Law, Edward Elgar Publishing, 142-159.

Leering, M. (2014). Conceptualizing Reflective Practice for Legal Professionals, Journal of Law and Social Policy, 23, 83-106.

Li, J. (2012). Cultural Foundations of Learning: East and West. Cambridge University Press.

Lynch, A. (1996). Why do we Moot? Exploring the Role of Mooting in Legal Education, Legal Education Review 7(1). Retrieved from http://www.austlii.edu.au/au/journals/LegEdRev/1996/3.html

Menkel-Meadow, C. (2001). Aha? Is Creativity Possible in Legal Problem Solving and Teachable in Legal Education? Harvard Negotiation Law Review, 6, 97-144.

Miller, C. J., McNear, J., \& Metz, M. J. (2013). A comparison of traditional and engaging lecture methods in a large, professional-level course, Advances in Physiology Education, 37(4), 347-355. 
Montgomery, J. E. (2007). Incorporating emotional intelligence concepts into legal education: strengthening the professionalism of law students. University of Toledo Law Review, 39, 323-352.

Nowrot, K. (2004). Global Governance and International Law. Retrieved from www.wirtschaftsrecht.unihalle.de/sites/default/files/altbestand/Heft33.pdf

Qafisheh, M. (2016). Experimental Legal Education in a Globalized World. UK: Cambridge Scholars Publishing.

Reed, J. W. (1999). The Changing Face of Legal Education: Implications for the Practice of Law and the Courts. Law Review, 3, 779-790.

RF President Decree (2014). Principles of State Policy of the Russian Federation in the sphere of legal literacy and legal awareness of citizens. Retrieved from http://www.rg.ru/2011/07/14/pravosoznaniedok

Sokhi-Bulley, B. (2016). Learning Law Differently: The Importance of Theory and Methodology. In: Bart van Klink, \& Ubaldus de Vries (Eds.), Academic Learning in Law, the Netherlands, Edward Elgar Publishing, 121-141.

Sommerlad, H., Harris-Short, S., Vaughan, S. \& Young, R. (2015). The Futures of Legal Education and the Legal Profession, UK: Bloomsbury Publishing.

Sturm, S., \& Guinier, L. (2007). The law school matrix: reforming legal education in a culture of competition and conformity. Vanderbilt Law Review, 60, 515-554.

Van Klink, B., de Vries, B. (2013). Skeptical Legal Education, Law and Method. Retrieved from https://www.bjutijdschriften.nl/tijdschrift/lawandmethod/2013/2/ReM_2212-2508_2013_003_002_004

Vanderstraeten, R. (2002). Dewey's transactional constructivism. Journal of Philosophy of Education, 36(2), $233-46$.

Webb, J. (1998). Ethics for lawyers or ethics for citizens? New directions for legal education. Journal of Law and Society, 25(1), 134-150.

\section{http://www.ejmste.com}

